\title{
CONTINUOUS MONOTONE MAPS ON MATRICES FOR ORDERS INDUCED BY THE GROUP INVERSE
}

\author{
Mikhail A. EFimov And AleXander E. Guterman
}

Abstract. We characterize continuous injective maps on the set of complex matrices which are monotone with respect to $\stackrel{\sharp}{\leqslant}$-order or $\stackrel{\text { cn }}{\leqslant}$-order. In particular, we prove that all such maps must be automatically $\mathbb{R}$-linear and surjective. We also present several examples of monotone maps showing that our assumptions are indispensable.

Mathematics subject classification (2010): 15A04.

Keywords and phrases: Monotone matrix maps, group inverse, matrix partial orders.

\section{REFERENCES}

[1] A. Ben-Israel, T. Greville, Generalized Inverses: Theory and Applications, John Wiley and Sons, New York (1974).

[2] I. I. Bogdanov, A. E. Guterman, Monotone matrix maps defined by the group inverse and simultaneous diagonalizability, Matematicheskii Sbornik [in Russian] 198, 1 (2007), 3-20. Translated by Sb. Math. 198, 1-2 (2007) 1-16.

[3] J. B. Conway, Functions of One Complex Variable I, second ed., Springer Verlag, New York (1991).

[4] G. Dolinar, J. Marovt, Star partial order on B(H), Linear Algebra Appl. 434, (2011), 319-326.

[5] G. Dolinar, A. Guterman, J. Marovt, Automorphisms of $K(H)$ with respect to the star partial order, Operators and Matrices 7, 1 (2013), 225-239.

[6] G. DolinaR, A. Guterman, J. MAROvT, Automorphisms of $B(H)$ with respect to the left-star and the right-star partial order, Mathematical Inequalities and Applications 17, 2 (2014), 573-589.

[7] M. A. Efimov, Linear matrix transformations that are monotone with respect to the $\stackrel{\sharp}{\leqslant}$ - or $\stackrel{c n}{\leqslant}$-order, Fundamentalnaya I Prikladnaya Matematika [in Russian] 13, 4 (2007), 53-66. Translated by Journal of Mathematical Sciences (New-York) 155, 6 (2008), 830-838.

[8] M. A. EFIMOV, Additive matrix maps that are monotone with respect to the orders induced by group inverse, Fundamentalnaya i Prikladnaya Matematika [in Russian] 17, 6 (2011/2012), 23-40. Translated by Journal of Mathematical Sciences (New-York) 193, 5 (2013), 659-670.

[9] M. A. EFImov, A. E. Guterman, Monotone maps on index one matrices, Zapiski POMI [in Russian] 405, (2012), 67-96. Translated by Journal of Mathematical Sciences (New-York) 191, 1 (2013), $36-51$

[10] M. A. Efimov, A. E. Guterman, Monotone maps on diagonalizable matrices, Mathematical Inequalities and Applications 17, 4 (2014), 1441-1452.

[11] R. E. HaRTwig, How to partially order regular elements, Math. Japonica 25, 1 (1980), 1-13.

[12] R. E. Hartwig, S. K. Mitra, Partial orders based on outer inverses, Linear Algebra Appl. 176, (1982), 3-20.

[13] P. LEGIŠA, Automorphisms of $M_{n}$, partially ordered by rank subtractivity ordering, Linear Algebra Appl. 389, (2004), 147-158.

[14] P. LEGIŠA, Automorphisms of $M_{n}$, partially ordered by the star order, Linear and Mult. Algebra. 54, 3 (2006), 157-188.

[15] S. K. Mitra, On group inverses and the sharp order, Linear Algebra Appl. 92, (1987), 17-37.

[16] K. S. S. NAMBOORIPAD, The natural partial order on a regular semigroup, Proceedings of the Edinburgh Math. Soc. 23, (1980), 249-260. 
[17] P. G. Ovchinnikov, Automorphisms of the poset of skew projections, J. of Functional Analysis 115, (1993), 184-189.

[18] C. R. RaO, S. K. Mitra, Generalized Inverse of Matrices and its Applications, Wiley, New York, (1971).

[19] P. ŠEMRL, Order-preserving maps on the poset of idempotent matrices, Acta Sci. Math. (Szeged) 69, (2003), 481-490.

[20] P. ŠEMrL, Non-linear commutativity preserving maps, Acta Sci. Math. (Szeged) 71, (2005), 781-819.

[21] P. ŠEMRL, Automorphisms of $B(H)$ with respect to minus partial order, J. Math. Anal. Appl. 369, (2010), 205-213.

[22] B. V. ShaBAT, Introduction to complex analysis, Nauka, Moscow, (1969), [in Russian]. Translation is available at http://en.books4study.biz/f3067.html, http://math.stanford.edu/ $\sim$ ryzhik/shabat-all.pdf. 